\title{
Trends in Neurosurgical Management of Traumatic Brain Injury in Colombia
}

\author{
${ }^{1}$ Luis Rafael Moscote, ${ }^{2}$ Claudia Marcela Restrepo Lugo, ${ }^{3}$ Sandra Castellar, ${ }^{4}$ Gabriel Alcala \\ ${ }^{5}$ Juan Carlos Puyana, ${ }^{6}$ Andres Mariano Rubiano
}

\begin{abstract}
Introduction: Traumatic brain injury (TBI) is a public health problem with higher impact in low and middle income countries. Surgical management of TBI in Colombia is a common intervention performed by neurosurgeons but there is little knowledge about their preferences and trends during the care.
\end{abstract}

Materials and methods: We designed a 19 questions survey based on previous studies in high income settings. Through the Colombian Association of Neurosurgery website contact list, we submit the survey to 324 registered neurosurgeons. Statistical analysis was performed using frequencies of nominal and quantitative data.

Results: The response number was 47 (14.8\%). Around 97.8\% were males and $66 \%$ have more than 5 years in practice. Thirty percent operate between 50 and 100 cases of TBI and $65.9 \%$ work in at least two facilities. The $95.74 \%$ consider that trauma surgery is not well paid by the system. Only $12.5 \%$ of the neurosurgeons are more devoted to neurotrauma and $20.8 \%$ are practicing more spine surgery. The $36.1 \%$ will choose not to do trauma neurosurgery if they have the opportunity. Resources for emergency craniotomies in their facilities were considered adequate by $93.6 \%$ of the responders.

Conclusion: Caring for patients with neurotrauma is not an attractive option for some practicing neurosurgeons in Colombia. Traumatic brain injury cases are frequent in daily practice but some neurosurgeons prefer not to do trauma surgery if they have the option. Institutions have basic resources to perform trauma neurosurgery but the surgery is not well paid by the health system according to the neurosurgeons perspective.

\footnotetext{
${ }^{1}$ Neurosurgeon, ${ }^{2,4}$ Resident Physician, ${ }^{3}$ Medical Doctor

${ }^{5}$ Trauma and Critical Care Surgeon, ${ }^{6}$ Neurosurgeon and Professor of Neurosciences

${ }^{1,3,4}$ Department of Neurological Surgery, University of Cartagena, Colombia

${ }^{2}$ Department of Neurological Surgery Service, Central Military Hospital, Bogotá, Colombia

${ }^{5}$ Department of Trauma and Critical Care, University of Pittsburgh Medical Center, Pittsburgh, USA

${ }^{6}$ Department of Neurosurgery and Critical Care, South Colombian University, Neiva University Hospital, Huila Colombia
}

Corresponding Author: Andres Mariano Rubiano Neurosurgeon, Professor of Neurosciences, Department of Neurosurgery and Critical Care, Neiva University Hospital Huila, Colombia, Phone: 573132514132, e-mail: rubianoam@ gmail.com
Keywords: Head trauma, Survey, Neurosurgery, Neurotrauma, Traumatic brain injury.

How to cite this article: Moscote LR, Lugo CMR, Castellar S, Alcala G, Puyana JC, Rubiano AM. Trends in Neurosurgical Management of Traumatic Brain Injury in Colombia. Panam J Trauma Crit Care Emerg Surg 2014;3(1):23-28.

Source of support: Nil

Conflict of interest: None

\section{RESUMEN}

Introducción: El trauma craneoencefálico es un problema de salud pública que genera un mayor impacto en países de bajos y medianos ingresos. El tratamiento quirúrgico de la lesión traumática cerebral es una intervención común realizada por los neurocirujanos, pero existe poco conocimiento acerca de las preferencias y las tendencias al brindar este cuidado en Colombia.

Materiales y métodos: Se diseñó un estudio de 19 preguntas basadas en estudios previos realizados en países de alto ingreso. A través de la página web de la Asociación Colombiana de Neurocirugía, se encuestó a 324 neurocirujanos registrados en esta página. Se realizó un análisis estadístico utilizando frecuencias de datos nominales y cuantitativos.

Resultados: El número de respuestas fueron 47(14,8\%). El $97,8 \%$ eran hombres y el $66 \%$ tenían más de 5 años en la práctica médica. El $30 \%$ interviene entre 50 y 100 casos de trauma craneoencefálico al año y el $65,9 \%$ trabaja en por lo menos dos instituciones de salud. El 95,74\% considera que la cirugía de trauma no está bien remunerada por el sistema de salud colombiano. Sólo $12,5 \%$ de los neurocirujanos están dedicados a neurotrauma y el $20,8 \%$ están dedicados a cirugía de columna. El $36,1 \%$ decidiría no hacer neurocirugía de trauma si tuvieran la oportunidad. El 93,6\% de los encuestados considera que actualmente tiene los recursos apropiados para realizar craneotomías de emergencia en sus instituciones.

Conclusión: El cuidado de los pacientes con trauma neurológico no es una opción atractiva para algunos neurocirujanos en Colombia. Los casos de lesión traumática cerebral son frecuentes en la práctica diaria, pero algunos neurocirujanos preferirían no hacer cirugía de trauma si tuvieran la opción. Las instituciones de salud tienen actualmente los recursos básicos para llevar a cabo el manejo neuroquirúrgico del trauma, pero la cirugía no está bien remunerada por el sistema salud Colombiano de acuerdo a las expectativas de los neurocirujanos encuestados.

Palabras claves: Trauma de cráneo, Encuesta, Neurocirugía, Neurotrauma, Trauma craneoencefálico. 


\section{INTRODUCTION}

The World Health Organization (WHO) has been evaluating epidemiological data with the objective of identifying critical factors related to trauma morbidity and mortality worldwide. Trauma has increased significantly in the last several decades and approximately 16,000 people die every day all around the globe as a result of some traumatic injury, and for each one of these deaths many others are severely disabled. ${ }^{1}$ Motor vehicle-related collisions (MVCs) are the second most common cause of death worldwide in the age range of 15 to 30 years and interpersonal violence is the sixth most common cause of death for 15 to 30-year-old. Ninety percent of the mortality and morbidity caused by trauma is concentrated in low- and middle-income countries, especially in Latin America, Africa and Asia. ${ }^{1}$ Colombia is one of the Latin American countries with highest rates of violence due to the war on drugs and the internal social conflict.

According to the National Legal Medicine Institute from Colombia, in 2011, 25,709 people died due to violence, motor vehicle accidents and nonintentional accidents. In the same year 294,267 people were injured due to the same causes plus home/domestic related violence. This means that in 2011 , near 70 people die and 800 were injured every day. ${ }^{2}$ Close to $70 \%$ of the people who dies and $40 \%$ of the injured had an associated head injury. ${ }^{1}$ In a survey (2007) of the American Association of Neurological Surgeons, evaluating the allocation and availability of neurosurgeons worldwide, it was identified that neurosurgeons were concentrated in main cities, without appropriate coverage in rural zones and intermediate suburban cities. This phenomenon was more pronounced in low and middle-income countries. ${ }^{3}$ This document shows that around 23,940 neurosurgeons were available for the entire world population, approximately one for each 230,000 inhabitants. Fifty percent of these neurosurgeons are concentrated in countries of high and high medium income, and they cover only 30 to $40 \%$ of the world's population, whereas in low and low-middle income countries neurosurgeons cover approximately 60 to $70 \%$ of the actual trauma population. ${ }^{3}$

Just in the United States, nearly $20 \%$ of neurosurgeons who are in charge of neurotrauma cases would prefer not to do it, due to issues of financial reimbursement, medical liability and impact on elective practice, according to another survey of the American Association for Trauma Surgery 10 years ago. ${ }^{4}$ More recent studies exposed a crisis in the delivery of care for neurotrauma in specific areas as southern Texas because of the same reasons described 10 years before. ${ }^{5}$

Our objective was to evaluate the preferences and trends in neurosurgical care of traumatic brain injury (TBI) in
Colombia; a country where TBI is a public health problem, availability of neurosurgeons is limited, especially in rural areas and the healthcare system is in crisis. We hypothesized that lack of organized regional trauma systems and inappropriate reimbursement of medical care to physicians and hospitals may play a major role in the motivation for care from neurosurgeons and the quality of care for neurotrauma patients in Colombia.

\section{MATERIALS AND METHODS}

A 19-question survey was designed in a web platform. All 324 members registered in the web site of the Colombian Association of Neurosurgery.

Association of neurosurgery was contacted. The survey asked for administrative and technical aspects of the neurotrauma surgery including: affiliation, demographic and training characteristics, facilities, administrative issues of the health system and resources and technical preferences in the practice of neurotrauma surgery. These questions were formulated for adult and pediatric population. Answers were analyzed using SPSS 17.0 software (SPSS, Inc. Chicago, IL). Analysis of frequency and nominal or quantitative data was performed.

\section{RESULTS}

The survey was available on line for a 2 months period, from January to March of 2012. The available population included 324 registered neurosurgeons from the Colombian Association of Neurosurgery. This association is the only local association for specialists graduated from neurological surgery training programs that practice in Colombia. Fortyseven responses were received from 324 e-mails ( $14.8 \%$ response rate). Forty-six (97.8\%) of the respondents were men compared to only one email received from a woman $(2.2 \%)$.

Answers regarding neurosurgical practice are shown in Table 1.

There were $72.3 \%$ of the respondents who practiced general neurosurgery without subspecialty training; $20.8 \%$ were spine neurosurgeons. Only $12.5 \%$ consider their selves more devoted to trauma neurosurgery. Sixty-six percent have more than 5 years of experience in neurosurgery and $19.1 \%$ more than 15 years. Close to $80 \%$ were trained in Colombia; $65.9 \%$ of the respondents worked in public and private institutions at the same time, and only $4.2 \%$ worked exclusively in a public hospital. Seventy two percent works in a nonacademic environment, including pre or postgraduate neurological surgery training programs.

Answers regarding neurotrauma surgery are presented in (see Table 1). 
Table 1: Neurosurgical practice

\begin{tabular}{|c|c|}
\hline Question & No. (\%) \\
\hline \multicolumn{2}{|l|}{ Gender } \\
\hline Male & $46(97.8)$ \\
\hline Female & $1(2.2)$ \\
\hline \multicolumn{2}{|l|}{ How many TBI cases did you manage per year? } \\
\hline $10-50$ & $24(50)$ \\
\hline $50-100$ & $14(30)$ \\
\hline$>100$ & $9(20)$ \\
\hline \multicolumn{2}{|l|}{ Years of experience } \\
\hline $1-5$ & $7(14.9)$ \\
\hline $5-10$ & $34(66)$ \\
\hline More than 15 & $9(19.1)$ \\
\hline \multicolumn{2}{|l|}{ Country of training in general neurosurgery } \\
\hline Colombia & $37(78.7)$ \\
\hline Other & $10(21.27)$ \\
\hline \multicolumn{2}{|c|}{ Are you a part of any postgraduate training in neurosurgery? } \\
\hline Yes & $13(27.6)$ \\
\hline No & $34(72.3)$ \\
\hline \multicolumn{2}{|c|}{ Do you agree that other specialties perform urgency craniotomies? } \\
\hline Yes & $0(0)$ \\
\hline No & $47(100)$ \\
\hline \multicolumn{2}{|c|}{ With which of the following do you feel closer to in your day to day? You can select more than one option. } \\
\hline General neurosurgery & $16(33.3)$ \\
\hline Spine neurosurgery & $10(20.8)$ \\
\hline Trauma neurosurgery & $6(12.5)$ \\
\hline Oncology neurosurgery & $2(4.2)$ \\
\hline No answer & $11(22.9)$ \\
\hline Pediatric neurosurgery & $0(0)$ \\
\hline Vascular neurosurgery & $0(0)$ \\
\hline \multicolumn{2}{|c|}{ Do you consider that the neurosurgeon in charge of the patient should be in front of his/her follow-up? } \\
\hline Yes & $43(91.4)$ \\
\hline No & $3(6.38)$ \\
\hline No answer & $1(2.12)$ \\
\hline \multicolumn{2}{|c|}{ Who does the follow-up in a patient with a craniectomy for TBI? } \\
\hline The neurosurgeon who performed the surgery & $40(85.1)$ \\
\hline Another neurosurgeon & $3(6.38)$ \\
\hline No answer & $4(8.51)$ \\
\hline \multicolumn{2}{|c|}{ In the institution where you work, is it frequent to place intracranial pressure monitors for patients with TBI? } \\
\hline Yes & $22(46.8)$ \\
\hline No & $1(2.12)$ \\
\hline No answer & $24(51)$ \\
\hline \multicolumn{2}{|c|}{ At your workplace, another specialty different to neurosurgery does place intracranial pressure monitors? } \\
\hline Yes & 0 \\
\hline No & $47(100)$ \\
\hline \multicolumn{2}{|c|}{ Do you consider that it should be allowed, that different services to neurosurgery place intracranial pressure monitors? } \\
\hline Yes & $1(2.12)$ \\
\hline No & $46(97.8)$ \\
\hline
\end{tabular}

Note: The questions and answers related to neurosurgical practice associated to neurotrauma in Colombia. Answers include the number of respondents and percentage over the total number $(n=47)$

All respondents agreed that only neurosurgeons need to be allowed to perform urgent craniotomies. Half of respondents managed around 10 to 50 cases of head trauma, $30 \%$ between 50 and 100 and $20 \%$ more than 100 . The majority thought that the same surgeon who performed the urgent craniotomy should be in charge of the cases and of the follow-up of the patient.
Answers related to intracranial pressure (ICP) monitoring issues are presented in Table 1.

Regarding the use of ICP monitoring, $46.8 \%$ of the neurosurgeons stated that ICP monitors for patients with TBI are frequent in their institutions. However, $51 \%$ did not answer that question. All respondents stated that only neurosurgeons put intracranial pressure devices for monitoring at 
their institutions, and $97.8 \%$ thought that it should not need to be allowed that non-neurosurgeons insert ICP monitors.

Answers related to pediatric traumatic brain injury are shown in Table 2.

According to the survey, $89.1 \%$ of respondents agreed that neurosurgeons should be in charge of the follow-up of pediatric patients with TBI after a craniotomy. The team leader should be a neurosurgeon according to the $46.8 \%$, even if there are extra cranial injuries. Intensivists should be the leaders according to $42.5 \%$.

Answers related to administrative problems for neurotrauma surgery in Colombia are presented in Table 3.

Most (93.6\%) stated that there are not difficulties related to resources availability to perform urgent craniotomies at their institutions and $95.7 \%$ of respondents believed that neurotrauma surgery should have a higher economic remuneration by the Colombian health system and $25.5 \%$ of the neurosurgeons would choose not to perform neurotrauma surgery if the work contract will allow it. Around $42.5 \%$ did not answer that question.

\section{DISCUSSION}

Trauma has increased significantly worldwide and specially in low and middle-income countries. Neurotrauma is far away the leading cause of death in this patient's group. ${ }^{1}$ TBI is one of the more frequent pathologies seen by neurosurgeons day by day in low and middle-income settings and their surgical management, especially in some subgroups like epidural hematoma is one of the most cost effective surgical procedures. ${ }^{6}$ But far from the facts, there are still several gaps between the burden of the problem and the organization of the system for appropriate care of these patients, especially in low and middle income settings. ${ }^{7-9}$

Worldwide, the availability of neurosurgeons is tight and they are mostly concentrated in high income environments and in urban areas. ${ }^{3}$ This is a real world scenario and mechanisms to improve this problem are not yet visualized. Several efforts have been made in order to develop small focused global health neurosurgical teams, traveling to some rural areas or low income countries but most of them are more interested on infectious neurosurgical diseases or congenital neurosurgical abnormalities. ${ }^{10}$ Additionally, there is a lack of information, regarding the general consensus of neurosurgeons and their personal views related to why neurotrauma is not a 'hot topic' for the neurosurgical community, in part due or possibly due to the amount of cases and the related burden of disability and mortality worldwide. In 1997, Marion and Firlik performed a survey among the neurosurgeons of the American Association of Neurological Surgeons, to understand trends related to specific neurotrauma emergency care in the United States. ${ }^{11}$ In 2001,
Valadka et al performed a second survey with similar findings, identifying a phenomenon characterized by concentration of neurosurgeons in the main cities without an appropriate coverage of small cities and towns. They identified also a loose of interest in neurosurgeons to devote their practice to neurotrauma, arguing medical legal risks and life style restriction. ${ }^{4}$ This phenomenon has lead to proposals for restructuring the curriculum in other trauma-related specialist, specifically the acute care surgeons, suggesting to train acute care surgeons to perform neurotrauma operative emergencies, such as in

Table 2: Pediatrics

\begin{tabular}{|c|c|}
\hline Question & No. (\%) \\
\hline \multicolumn{2}{|c|}{$\begin{array}{l}\text { Related to pediatric patients with TBI and other } \\
\text { extracranial injuries, the follow-up should be } \\
\text { directed by? }\end{array}$} \\
\hline Intensivist & $20(42.51)$ \\
\hline Neurosurgeon & $22(46.8)$ \\
\hline Other & $4(8.51)$ \\
\hline No answer & $1(2.12)$ \\
\hline \multicolumn{2}{|c|}{$\begin{array}{l}\text { Regarding the treatment of pediatric patients } \\
\text { with traumatic brain injury, who do you believe } \\
\text { should perform the follow-up? }\end{array}$} \\
\hline Neurosurgeon & $42(89.3)$ \\
\hline Intensivist & $3(6.38)$ \\
\hline Pediatrician & $2(4.25)$ \\
\hline
\end{tabular}

Note: The questions and answers related to neurosurgical pediatric practice related to neurotrauma in Colombia. Answers include the number of respondents and percentage over the total number $(n=47)$

Table 3: Administrative questions

\begin{tabular}{ll}
\hline Question & No. (\%) \\
\hline What kind of institution do you work for? & $2(4.25)$ \\
Public institution & $15(31.9)$ \\
Private institution & $31(65.9)$ \\
Both & \\
In the institution where you work at, are & \\
there difficulties to perform an emergency & \\
craniectomy? & 0 \\
Yes & $44(93.6)$ \\
No & $3(6.38)$ \\
No answer & \\
Do you think that surgery for traumatic brain & \\
injury is well paid by the Colombian health & \\
system? & \\
Yes & $2(4.25)$ \\
No & $45(95.74)$ \\
If you have the opportunity of not to perform & \\
a surgery for traumatic brain injury in your & \\
work contract, would you choose this option & \\
or not? & \\
Yes & $12(25.5)$ \\
No & $17(36.1)$ \\
No answer & $20(42.5)$ \\
\hline
\end{tabular}

Note: The questions and answers related to administrative aspects of neurosurgical practice related to neurotrauma in Colombia. Answers include the number of respondents and percentage over the total number $(n=47)$ 
cases were neurosurgeons are not available and there is not an appropriate process for transfer a patient within a formal trauma care system. ${ }^{12-15}$

Based on this gap of knowledge, especially in low and middle-income areas, we developed this survey and not surprisingly we found the same trends for Colombia, a low middle-income country with a heavy burden of trauma and important numbers of disability and death due to traumatic brain injury. Several explanations can be made for the low survey response, but the lack of interest in the topic is an important one, taking into consideration that other surveys for different topics in the same group of neurosurgeons (e.g. financial issues of the association and administrative considerations of the healthcare system) had higher response rates. Regarding neurosurgical practice and neurotrauma surgery, there is a clear trend of male practitioners in a specialty that traditionally have been leaded by men and just recently start receiving more female applications for residency in the national programs. Most respondents are general neurosurgeons, explained for the lack of fellowship programs available locally, and consisting only in few spine fellows. There are no formal or informal national fellows for pediatrics, vascular, oncology, functional or even trauma and critical care neurosurgery.

Almost $80 \%$ have been trained locally and an important number is a young population, showing that $81 \%$ has between 1 and 15 years in practice. Only 19.1\% have more than 15 years of experience. Surprisingly while only $12.5 \%$ of the respondents consider their selves devoted to neurotrauma, more than $50 \%$ are facing more than 50 surgical traumatic brain injuries per year (including 20\% with more than 100 cases per year). It is clear that responders want to be in charge of neurotrauma cases, feeling that they need to perform neuro monitoring and ICU follow-up. This applies also for pediatric neurotrauma. Nevertheless, an important $25.5 \%$ prefer not to do neurotrauma if their contracts allow it and $42.5 \%$ did not answer that question. This need to be analyzed in conjunction with the $95.7 \%$ feeling that there is not appropriate reimbursement for neurotrauma surgery and also with the real situation of the increasing of medical legal risk in Colombia for emergency care due to the crisis of the healthcare system. Additionally, $72 \%$ of the respondents work in nonacademic institutions and this means they do not have support of residents or fellows for emergency care. This also means that when neurosurgeons are not in house, they are on call to take care of the emergencies at nights or during weekends. To have an idea, according to the 2011 national physician fee handbook from the Ministry of Health, the surgeon fee related to a trauma brain surgery craniotomy ranges between $\$ 277$ and \$350 USD. ${ }^{16,17}$
Unfortunately, the real scenario in Colombia indicates that several TBI cases are requiring specialized care every day. Several nonmotivated, not subspecialized and not wellremunerated neurosurgeons are taking care of these patients without the structure of a formal trauma care system, especially in public hospitals. Recently in a worldwide survey about prehospital trauma care in 13th different countries, we stated the effort that Colombia has made to improve EMS care, but we are still far from instituting definitive appropriate trauma care especially in rural areas. ${ }^{7}$ Organized trauma systems have been a real issue that impact care and have been demonstrated as a key factor in neurotrauma research within high income settings. ${ }^{18-21}$

With the aim to improve the total process of neurotrauma care, it is necessary to create better strategies for treatment within this real world scenario. In order to implement an efficient trauma system, basic organization is required, introducing low cost resources, such as infrastructure and policies for early and appropriate transfer to hospitals acting as trauma centers. Also, the development of trauma quality improvement programs in rural areas. For instance, a program for motivation in neurotrauma to neurosurgeons, neurosurgery residents, general surgeons and surgery residents in training should be implemented. It is urgent to promote a national level discussion in Colombia about policies, administrative and government issues related to surgical emergency care and specially neurotrauma.

\section{CONCLUSION}

Neurosurgery for traumatic brain injury is not a hot topic in Colombia despite of being a major health problem. There is a phenomenon seen in neurosurgeons in Colombia who prefer to perform the procedures than to manage head trauma. This is seen due to the health crisis in low-income countries. As a consequence, in countries like Colombia, there are difficulties in fully integrating the resources for care if the local and regional trauma systems are poorly structured. At the moment, it is perceived dissatisfaction from neurological surgeons in Colombia to manage patients with head trauma because they consider it has been not well paid and recognized by the health system. As an important fact, the majority of neurosurgeons believes that they should be in charge of the postoperatory follow-up of their patients.

\section{REFERENCES}

1. Lozano R, Naghavi M, Foreman K, Lim S, Shibuya K, Aboyans V, Abraham J, Adair T, Aggarwal R, Ahn SY. Global and regional mortality from 235 causes of death for 20 age groups in 1990 and 2010: a systematic analysis for the Global Burden of Disease Study 2010. Lancet 2013;380(9859):2095-2128.

2. National Institute of Legal Medicine. Colombia, 2011 Violence Report. Data for Life (in Spanish). Forensis, 2011;1:1-450. 
3. Nasser R, Jallo J. International Neurotrauma. AANS, Neurotrauma and Critical Care Section Newsletter. 3: 1 10. 2007. Available at: www.neurotraumasection.org/_literature 131289/2007_Fall_Edition. Accessed January 5, 2013.

4. Valadka A, Andrews BT, Bullock MR. How well do neurosurgeons care for trauma patients? A survey of the membership of the American for Association the Surgery of Trauma. Neurosurgery 2001;(48):17-25.

5. Cohn SM, Price MA, Stewart RM, Michalek JE, Dent DL, McFarland MJ, Pruitt BA Jr. A crisis in the delivery of care to patients with brain injuries in South Texas. J Trauma 2007; 62(4):951-962.

6. Lee EJ, Hung YC, Wang LC, Chung KC, Chen HH. Factors influencing the functional outcome of patients with acute epidural hematomas: analysis of 200 patients undergoing surgery. J Trauma 1998;45(5):946-952.

7. Colombian Ministry of Health, National Handbook of Medical Fees 2011 (in Spanish): Available at: http://www.idesac.gov. co. Accessed on January 8, 2013.

8. Hyder AA, Wunderlich CA, Puvanachandra P, Gururaj G, Kobusingye OC. The impact of traumatic brain injuries: a global perspective. Neurorehabilitation 2007;22:341-353.

9. Reilly P. The impact of neurotrauma on society: an international perspective. Prog Brain Res 2007;161:3-9.

10. Härtl R, Ellegala DB. Neurosurgery and global health: going far and fast, together: World Neurosurg 2010;73(4):259-260.

11. Marion DW, Firlik K. Management of severe traumatic brain injury in 1997: the impact of the guidelines for the management of severe head injuries. AANS/CNS Section of Neuro-trauma and Critical Care. Newsletter, Summer/Fall 1997;2:2-3.

12. Esposito T, Reed L, Gamelli R, Luchette F. Neurosurgical coverage: for essential, desired or irrelevant good trauma care and trauma to center status. Annals of Surgery 2005;242:364-374.
13. Esposito TJ, Luchette FA, Gamelli RL. Do we need neurosurgical coverage in the trauma center? Adv Surg 2006;40:213-221.

14. Havill J, Sleigh J. Management and outcomes of patients with brain trauma in a tertiary referral trauma hospital without neurosurgeons on site. Anaesth Intensive Care 1998;26:642-647.

15. Valadka AB, Ellenbogen RG, Wirth FP Jr, Laws ER Jr. Acute care surgery: challenges and opportunities from the neurosurgical perspective. Surgery 2007;141(3):321-323.

16. De Silva MJ, Roberts I, Perel P, Edwards P, Kenward MG, Fernandes J, Shakur H, Patel V. CRASH Trial Collaborators. Patient outcome after traumatic brain injury in high-, middleand low-income countries: analysis of data on 8927 patients in 46 countries. Int J Epidemiol 2009;38(2):452-458.

17. Nielsen K, Mock C, Joshipura M, Rubiano AM, Zakariah A, Rivara F. Assessment of the status of prehospital care in 13 low and middleincome countries. Prehosp Emerg Care 2012;16(3):381-389.

18. Sánchez AI, Krafty RT, Weiss HB, Rubiano AM, Peitzman AB, Puyana JC. Trends in survival and early functional outcomes from hospitalized severe adult traumatic brain injuries, Pennsylvania, 1998 to 2007. J Head Trauma Rehabil 2012; 27(2):159-169.

19. Tiesman H, Young T, Torner JC, McMahon M, Peek-Asa C, Fiedler J. Effects of a rural trauma system on traumatic brain injuries. J Neurotrauma 2007;24(7):1189-1197.

20. Celso B, Tepas J, Langland-Orban B, Pracht E, Papa L, Lottenberg L, Flint L. A systematic review and meta analysis comparing outcome of severely injured patients treated in trauma centers following the establishment of trauma systems. J Trauma 2006;60(2):371-378.

21. DuBose J, Browder T, Inaba K, Teixeira PG, Chan LS, Demetriades D. Effect of trauma centers designation on outcome in patients with severe traumatic brain injury. Arch Surg 2008; 143:1213-1217. 